\title{
Analysis of Crystallographic Orientation Changes during Deformation of Magnesium Single Crystals
}

\author{
B. SUŁKOWSKI* \\ Department of Mater. Science and Engineering of Non-ferrous Metals, \\ AGH University of Science and Technology, Al. Mickiewicza 30, 30-059 Krakow, Poland
}

(Received December 16, 2013; in final form March 7, 2014)

\begin{abstract}
Magnesium single crystals of three different orientations were deformed by tension at room temperature to investigate the geometrical criterion resulting from the Schmid law for activation of basal and non-basal slip systems. Changes of crystallographic orientations of investigated single crystals were systematically measured during deformation and the geometrical criterion was examined in respect to the changes of crystallographic orientations during deformation. The geometrical criterion itself failed to explain lack of activity of non-basal slip systems in the deformed magnesium single crystals. Therefore the ratio of activation volumes of soft to hard slip systems is considered to be introduced for a better understanding of the deformation in hcp metals.
\end{abstract}

DOI: $10.12693 /$ APhysPolA.126.768

PACS: 61.72.Hh, 61.50.-f, 81.10.Aj, 61.50.Ah, 81.40.Ef

\section{Introduction}

To analyze deformation behaviors and flow stress in metals and metal alloys all possible slip modes and their activity during deformation have to be taken into account. For example, the knowledge of activity of slip systems in hcp metals can be very useful to better understand texture evolution during deformation $[1,2]$. To predict which slip mode will initiate the slip process the Schmid law defined as $\tau=\sigma m$ (where $m=\cos \chi \cos \lambda$ is a Schmid factor, $\chi$ angle between force and slip plan normal, $\lambda$ angle between force and slip direction) is used [35]. However, the application of the Schmid law to hcp metals is much more complicated than to the fcc metals because there are more than one type of slip systems with different critical resolved shear stresses (CRSSs) and a lot of twinning modes [6]. There are: basal slip system $\langle a\rangle$, prismatic slip system $\langle a\rangle$, pyramidal first $\langle a\rangle$, and second order $\langle c+a\rangle$ slip systems and twinning on $\{10 \overline{1} 2\}$ and $\{10 \overline{1} 1\}$ planes. Additionally, there are a lot of factors such as $c / a$ ratio, imposed stress, temperature and initial orientation which have influence on activation of particular slip mode like [7-12].

Munroe et al. [13] analyzed the Schmid factors in hcp metals and divided them in two groups: basal-slip metals $(c / a \geq 1.633, \mathrm{Zn}, \mathrm{Mg})$ and prismatic-slip metals $(c / a<1.633, \mathrm{Ti}, \mathrm{Zr})$, then the areas, where particular slip system was acting were specified inside the standard triangle. In case of the basal slip metals, the basal slip system is operating mainly in the center of the standard triangle. Crystals with orientations near [0001] direction $\langle c+a\rangle$ pyramidal slip system is dominant. Near $\langle 11 \overline{2} 0\rangle$ or $\langle 10 \overline{1} 0\rangle$ direction the $\langle a\rangle$ prismatic or $\langle c+a\rangle$ pyramidal slip system is acting, respectively. Nan et al. [14] systematically calculated the Schmid factors $m$ in magnesium under different loading directions for the basal

*e-mail: su15@agh.edu.pl

$\langle a\rangle$, prismatic $\langle a\rangle$, pyramidal $\langle a\rangle$, and $\langle c+a\rangle$ slip systems and two twinning modes $\{10 \overline{1} 2\}$ and $\{10 \overline{1} 1\}$. It was proposed that the easiest activation variant of slip mode for magnesium is the one with the highest $m$ value. Nan et al. [15] referred the Schmid factors of the different slip modes to the $c / a$ ratio in the hcp metals like $\mathrm{Cd}$, $\mathrm{Zn}, \mathrm{Zr}, \mathrm{Ti}, \mathrm{Be}$. The results indicate a negligible effect of $c / a$ ratio on Schmid factors for the basal and prismatic slip systems for all hcp metals. On the other hand, the experiments are showing the impact of $\mathrm{c} / \mathrm{a}$ ratio on the basal/prismatic slip activity in the hcp metals $[7-12,16]$. The basal slip system is dominant for the hcp metals with $c / a \geq 1.633[16]$ and prismatic slip system is dominant in the hcp metals with $c / a<1.633$ [11].

Additional difficulties arise from the fact that for some hcp metals Schmid law is not always obeyed, for example, in Ti single crystals during prismatic slip deformation as was reported by Akhtar and Teghtsoonian [17] or in magnesium alloy $\mathrm{Mg}-3 \mathrm{Al}-1 \mathrm{Zn}$ [18] where the behaviors of secondary twinning was assigned with non-Schmid effects. Thus, besides the Schmid factors, there is an additional parameter for activation of different slip modes in the hcp metals. Hutchinson and Barnet [19] analyzed the ratio of CRSSs hard to soft slip systems $\left(\tau_{\text {hard }} / \tau_{\text {soft }}\right)$ in magnesium. They found that if $\tau_{\text {hard }} / \tau_{\text {soft }} \gg 1$ then the soft slip system (basal in hcp) is dominant. Such a situation is observed e.g. in pure magnesium single crystals $[3,20]$. On the other hand, if the $\tau_{\text {hard }} \tau_{\text {soft }}$ decreases to 1, e.g. in Mg-alloys, hard slip mode becomes more favorable one [19]. Koike and Ohyama [20] investigated tensile anisotropy in hot-forged and subsequently hotrolled magnesium alloy AZ61. They found that at the room temperature the angle between the basal plane and loading axis is a geometrical criterion $(n)$ for the activation of the prismatic $\langle a\rangle$ slip mode. If $n<1.5$ only basal slip system is active while for $n<2$ both basal and prismatic slip systems operate. When basal and prismatic slip systems operate a larger deformation of the samples is observed in comparison to a situation, when only basal slip system is active [20]. 
Tyson [21] considered the preference for activation of basal or prismatic slip systems in hcp crystals under "energy factor" $(K)$. $K$ is dependent on the elastic constants and the choice of slip plane may be governed by the stress needed to move dislocation against the resistance of the lattice [21]. He concluded that elastic anisotropy and high theoretical value of stacking fault energy $\gamma_{\mathrm{b}}$ of two partial basal dislocations favour slip on prismatic plane in $\mathrm{Zr}, \mathrm{Ti}$ and $\mathrm{Hf}$ and low value of $\gamma_{\mathrm{b}}$ favours basal slip in Co. For the other hcp metals, due to lack of reliable data above criterion could not be validated.

Therefore, the criteria for the activation of basal and non-basal slip systems in the hcp metals need more theoretical and experimental investigations. This paper presents the investigations of crystallographic orientations changes during tensile deformation of pure magnesium single crystals and comparison with data of deformed titanium $(c / a=1.589)$ single crystals which can be found in the literature.

\section{Experiment and results}

Single crystals of magnesium (99.8 at.\%) were obtained from seed using the Bridgman method under argon atmosphere $(0.1 \mathrm{~atm})$. There were three different initial orientations (A, B and C) where angles between tensile direction (TD) and normal to (0001) plane were $25^{\circ}, 56^{\circ}$ and $77^{\circ}$ for each single crystal, respectively, (see Fig. 1a points $\mathrm{A} 0, \mathrm{~B} 0$ and $\mathrm{C} 0$ ). The initial orientations were

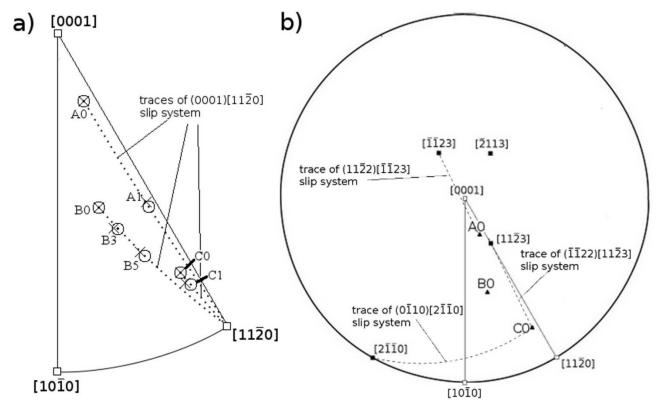

Fig. 1. The changes of crystallographic orientations of the investigated single crystals A, B and C, (a) before the deformation (points $\mathrm{A} 0, \mathrm{~B} 0$ and $\mathrm{C} 0$ ) and after teh deformation (A1, B3-B5 and C1, (b) results of simulations - traces of pyramidal and prismatic slip systems.

measured with use of the X-ray techniques where error of measurement was estimated for $\pm 1.5^{\circ}$. The Schmid factors for initial orientations of the single crystals A, $\mathrm{B}$ and $\mathrm{C}$ for basal, prismatic and pyramidal slip systems were calculated and are shown in Table I. In this study, the pyramidal first-order $(10 \overline{1} 1)\langle\overline{1} 010\rangle$ slip system was not considered because this slip system is activated in the magnesium single crystals at temperatures above $225{ }^{\circ} \mathrm{C}[22]$. The single crystals were prepared to observations at optical microscope by electro-polishing for 2 $h$ at room temperature in a solution of $\mathrm{H}_{3} \mathrm{PO}_{4}$ acid and ethanol (volume ratio $3: 5$ ) with a tantalum cathode operating at $3 \mathrm{~V}$.

The single crystals $\mathrm{A}, \mathrm{B}$ and $\mathrm{C}$ were deformed by tension at room temperature $\left(0.31 T_{\mathrm{m}}\right)$ at $10^{-3} \mathrm{~s}^{-1}$ strain rate. The crystallographic orientations after deformation of investigated single crystals were measured by X-ray diffraction technique. The orientations were measured with the error of $1.5^{\circ}$. The experimentally measured orientations after deformation of the single crystals $\mathrm{A}, \mathrm{B}$ and $\mathrm{C}$ are marked by crosses in Fig. $1 \mathrm{a}$ at points $\mathrm{A} 1$, B3-B5, C1, respectively. The related Schmid factors for slip basal, prismatic and pyramidal systems are listed in Table I.

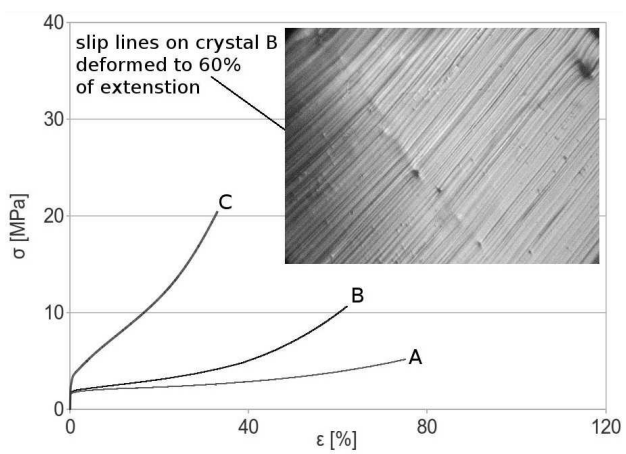

Fig. 2. Engineering stress-strain curves of the investigated magnesium single crystals A, B, and C.

Figure 2 shows engineering stress-strain curves for the investigated magnesium single crystals because considering Table $I$ is not clear which slip systems are primary and dominant. If the angle between TD and [0001] direction of the studied single crystals is increasing the rate of work hardening is also increasing. It was also observed, that only one type of slip lines were present during the deformation of $\mathrm{A}, \mathrm{B}$ and $\mathrm{C}$ single crystals investigated by the optical microscope.

The next step in this study were simulations of theoretical changes of TD if there was assumed deformation by single slip. TD moves toward slip direction of a primary slip system during single slip of tensioned crystal [23]. The vector $V^{D}$ after $\gamma$ shear strain can be calculated from Eq. (1):

$$
V^{D}=D V \text {, }
$$

where $V$ is a vector before the deformation, $D$ is deformation matrix $(3 \times 3)$ which is expressed as:

$$
D=I+\gamma s_{d} s_{n}^{\mathrm{T}},
$$

where $I$ is the identity matrix, $s_{d}$ and $s_{n}$ are the unity vectors of slip direction and normal to slip plane of active slip system.

The glide shear strain can be determined from initial orientation from slip plane $\left(\chi_{0}\right)$, slip direction $\left(\lambda_{0}\right)$ and extension of sample $L_{i} / L_{0}$ as is expressed by the equation:

$$
\gamma=\frac{1}{\sin \chi_{0}}\left\{\left[\left(\frac{L_{i}}{L_{0}}\right)^{2}-\sin ^{2} \lambda_{0}\right]^{1 / 2}-\cos \lambda_{0}\right\} .
$$

Calculated shear strains (Eq. (3)), in respect of initial orientation, for $\mathrm{A}$ and $\mathrm{C}$ single crystals rotated to positions $\mathrm{A} 1$ and $\mathrm{C} 1$ were 1.24 and 1.41 , respectively. With respect to the initial crystallographic orientation of the 
deformed crystal $\mathrm{B}$, the shear strains were $0.1,0.2,0.4$, 0.8 , and 1.2 at positions B1-B5, respectively. The simulations were performed in the way that the vectors $V^{D}$ describing the crystallographic orientations after deformation of the single crystals A, B and C for basal (empty circles in Fig. 1a), prismatic and pyramidal (dotted lines in Fig. 1b) slip systems were calculated from vectors
$V$ of initial crystallographic orientations (positions A0, B0 and C0, Fig. 1a) using formulae (1) and (2) and $\gamma$ for each single crystal. In all cases, it was assumed that deformation proceeded only by a single slip. Empty circles in Fig. 1a cover the error of $1.5^{\circ}$ around calculated directions.

TABLE I

Schmid factors for the investigated magnesium single crystals of the orientations A, B, and C.

\begin{tabular}{c|c|c|c|c|c|c|c|c|c|c}
\hline \hline & A0 & A1 & B0 & B1 & B2 & B3 & B4 & B5 & C0 & C1 \\
\hline strain $\rightarrow$ & 0 & $33 \%$ & $0 \%$ & $5 \%$ & $10 \%$ & $20 \%$ & $40 \%$ & $60 \%$ & 0 & $60 \%$ \\
\hline$(0001)[11 \overline{2} 0]$ & 0.37 & 0.44 & 0.45 & 0.43 & 0.43 & 0.41 & 0.35 & 0.33 & 0.22 & 0.19 \\
$(0001)[2 \overline{1} \overline{1} 0]$ & 0.24 & 0.24 & 0.34 & 0.33 & 0.31 & 0.29 & 0.24 & 0.21 & 0.12 & 0.10 \\
$(0001)[\overline{1} 2 \overline{1} 0]$ & 0.13 & 0.21 & 0.11 & 0.10 & 0.11 & 0.11 & 0.12 & 0.12 & 0.10 & 0.08 \\
$(1 \overline{1} 00)[11 \overline{2} 0]$ & 0.03 & 0.03 & 0.19 & 0.20 & 0.19 & 0.18 & 0.16 & 0.14 & 0.05 & 0.05 \\
$(0 \overline{1} 10)[2 \overline{1} \overline{1} 0]$ & -0.08 & -0.33 & -0.34 & -0.35 & -0.37 & -0.39 & -0.42 & -0.43 & -0.43 & -0.44 \\
$(10 \overline{1} 0)[\overline{1} 2 \overline{1} 0]$ & 0.06 & 0.30 & 0.15 & 0.16 & 0.18 & 0.20 & 0.26 & 0.26 & 0.38 & 0.39 \\
$(11 \overline{2} 2)[\overline{1} \overline{1} 23]$ & 0.46 & 0.00 & 0.06 & 0.03 & 0.01 & -0.04 & -0.14 & -0.17 & -0.30 & -0.33 \\
$(\overline{1} 2 \overline{1} 2)[1 \overline{2} 13]$ & 0.42 & 0.14 & 0.17 & 0.16 & 0.15 & 0.13 & 0.08 & 0.06 & -0.02 & -0.03 \\
$(\overline{2} 112)[2 \overline{1} \overline{1} 3]$ & 0.23 & -0.08 & -0.17 & -0.19 & -0.19 & -0.20 & -0.20 & -0.20 & -0.16 & -0.16 \\
$(\overline{1} \overline{1} 22)[11 \overline{2} 3]$ & 0.13 & -0.40 & -0.34 & -0.36 & -0.38 & -0.41 & -0.46 & -0.47 & -0.50 & -0.50 \\
$(1 \overline{2} 12)[\overline{1} 2 \overline{1} 3]$ & 0.30 & -0.04 & 0.08 & 0.07 & 0.05 & 0.02 & -0.02 & -0.04 & -0.11 & -0.11 \\
$(2 \overline{1} \overline{1} 2)[\overline{2} 113]$ & 0.45 & 0.13 & 0.13 & 0.11 & 0.10 & 0.06 & 0.01 & -0.01 & -0.05 & -0.07
\end{tabular}

\section{Discussion}

Comparing calculated orientations with experimentally measured ones (Fig. 1a - crosses and open circles), in all cases TD moves toward [1120] direction of the primary basal (0001)[11 $\overline{2} 0]$ slip system. With respect to the basal slip system, the Schmid factors were larger or even twice larger for the pyramidal $(11 \overline{2} 2)[\overline{1} \overline{1} 23],(2 \overline{1} \overline{1} 2)[\overline{2} 113]$ slip systems in case of the single crystal A and for the

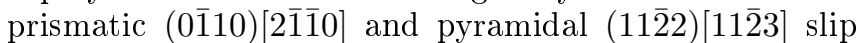
systems in case of the single crystal C (see Table I), de-

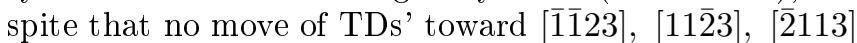
or [2 $\overline{1} \overline{1} 0]$ direction was observed. The very interesting result was noticed for the crystal $B$. In this case, before deformation, the crystal had the highest value of the Schmid factor $(m=0.49)$ for $(0001)[11 \overline{2} 0]$ slip system. During deformation $m_{\text {basal }}$ was decreasing for that crystal (see Table I) and at position B4 the highest absolute Schmid factor was for the pyramidal $(11 \overline{2} \overline{2})[11 \overline{2} 3]$ slip system, but any significant change of TD toward [11 $\overline{2} 3]$ direction was not observed.

The CRSS of (0001)[11리 slip system was $0.46 \mathrm{MPa}$, $0.59 \mathrm{MPa}$ and $0.49 \mathrm{MPa}$ for the single crystals $\mathrm{A}, \mathrm{B}, \mathrm{C}$, respectively. The mean value is $0.51 \pm 0.07 \mathrm{MPa}$, which is in a good agreement with literature [24].

In this study non-basal slip systems in the deformed single crystals A, B and C were not activated. Reed-Hill and Robertson [25] observed activation of prismatic slip system in the magnesium single crystals oriented parallel to $\langle 10 \overline{1} 0\rangle$ direction. Obara et al. [6] observed activation of pyramidal slip system $(\overline{1} \overline{1} 22)\langle 11 \overline{2} 3\rangle$ as sec- ondary one in the compressed magnesium single crystals of orientation very close to $c$ axis. In both investigations $m_{\text {non-basal }} / m_{\text {basal }} \gg 1$ satisfied the geometrical criterion for activation of non-basal slip system in magnesium $[14,20]$. For the initial orientations of crystals A and $\mathrm{C}$ in this study $m_{\text {non-basal }} / m_{\text {basal }}$ was 1.24 and 2.27 , respectively, but no activation of the non-basal slip system was observed. Hence, the above geometrical criterion was not satisfied [14, 20].

Activation volume is a function of shear stress, $V^{*}=$ $f(1 / \tau)$, so Eq. (5) in [14] can be expanded to

$$
\frac{\tau_{\text {prism }}}{\tau_{\text {basal }}} \equiv \frac{V_{\text {basal }}^{*}}{V_{\text {prism }}^{*}} \text {. }
$$

To minimize work done by the moving dislocation, that slip system will be activated in which moving dislocation overcomes less obstacles. The expanded criteria for activation of non-basal slip systems in hcp metals are the ratio of the Schmid factors $m_{\text {non-basal }} / m_{\text {basal }} \geq 1[14,20]$ and the ratio $V_{\text {basal }}^{*} / V_{\text {non-basal }}^{*} \leq 1$.

Considering basal and prismatic slip in hcp metals. Akhtar and Teghstoonian [24] found that at $78 \mathrm{~K}$ in high purity magnesium single crystals at the beginning of deformation $V_{\text {basal }}^{*}$ is $4.5 \times 10^{3} b^{3}, b$ is the Burgers vector. Bhattacharya and Niewczas [26] found $V_{\text {basal }}^{*}=900 b^{3}$ at room temperature for the high purity of magnesium single crystals. Butt et al. [27] investigated plastic flow in the Mg-alloyed single crystals and found that $V_{\text {basal }}^{*}$ is decreasing with increasing concentration of alloying elements. 
In case of prismatic slip [28] $V_{\text {prism }}^{*}$ at $78 \mathrm{~K}$ was $80 b^{3}$. The increase of temperature to $293 \mathrm{~K}$ caused increase of $V_{\text {prism }}^{*}$ to $200 b^{3}$. At $78 \mathrm{~K}$, the ratio of $V_{\text {basal }}^{*} / V_{\text {prism }}^{*}$ is 56.25 while at room temperature is 3 . At the range of temperatures between 77 and $300 \mathrm{~K}$ for large spectrum of orientations only basal slip system is activated in the high purity magnesium single crystals $[3,16,26]$.

The $c / a$ ratio has no effect [15] on the Schmid factors for basal and prismatic slip in $\mathrm{Mg}(c / a=1.624)$ and $\operatorname{Ti}(c / a=1.589)$ single crystals of similar orientations. The titanium single crystals of various orientations were investigated by Akhtar [17, 29], who found out that above $500 \mathrm{~K}\left(0.26 T_{\mathrm{m}}\right)$ the basal slip system is dominant [29]. The TD (similar to B0 in this study) of the deformed $\mathrm{Ti}$ single crystal moved from the initial position, where $m_{\text {prism }} / m_{\text {basal }}=0.49$ (see Fig. 9 in [29]) toward [11̄20] slip direction of the primary basal slip system. At position where $m_{\text {prism }} / m_{\text {basal }}=0.8$ (similar to B4) a change from the primary basal (0001)[112̄0]

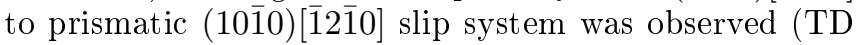
moves toward [1210] direction). Akhtar [29] found that at $500 \mathrm{~K} V_{\text {basal }}^{*} \approx 150 b^{3}$ while $V_{\text {prism }}^{*}$ is $\approx 170 b^{3}$ [17]. In case of $\mathrm{Ti}, V_{\text {basal }}^{*} / V_{\text {prism }}^{*} \approx 0.88$ at $0.26 T_{\mathrm{m}}$. The ratio $V_{\text {basal }}^{*} / V_{\text {prism }}^{*}<1$ for the Ti single crystals, thus the prismatic slip system was activated.

Based on the data provided by Akthar and Teghstoonian [24] and Butt [27] the ratio of $V_{\text {basal }}^{*} / V_{\text {prism }}^{*}$ can be estimated for magnesium single crystals of purity $99.8 \%$. The data are summarized in Table II. TABLE II

Values of activation volume $V^{*}$ for basal and prismatic slip system for $\mathrm{Mg}$.

\begin{tabular}{l|c|c}
\hline \hline & $V^{*}\left[b^{3}\right]$ & Ref. \\
\hline basal slip system & 2148 & Butt [27] \\
prismatic slip system & 200 & Akhtar [24]
\end{tabular}

For all single crystals $\mathrm{A}, \mathrm{B}$ and $\mathrm{C}$ the estimated ratio $V_{\text {basal }}^{*} / V_{\text {prism }}^{*}=10.74$ at the beginning of deformation. The ratio $V_{\text {basal }}^{*} / V_{\text {prisms }}^{*}>1$ can be associated with no activation of prismatic slip system in the studied magnesium single crystals A and C despite $m_{\text {prism }} / m_{\text {basal }}>1$.

Summarizing, the criteria for activation of basal and non-basal slip systems in the deformed magnesium single crystals of three different orientations were investigated. The introduced ratio of $V_{\text {basal }}^{*} / V_{\text {prism }}^{*}$ in combination with ratio of $m_{\text {prism }} / m_{\text {basal }}$ gave information about dominant slip mode in hcp metals as it was discussed for the $\mathrm{Mg}$ $(c / a=1.624)$ and $\operatorname{Ti}(c / a=1.589)$ deformed single crystals. The proposed criteria may be used for explanation of the deformation and the texture evolution in hcp metals.

\section{Acknowledgments}

The author would like to thank Prof. Borys Mikułowski from AGH-University of Science and Technology for constructive discussions.

The project was performed within the framework of the statutory activity (11.11.180.653) of Department of Mater. Science and Non-Ferrous Metals Engineering at University of Science and Technology, Kraków, Poland.

\section{References}

[1] B. Srinivasarao, N.V. Dudmell, M.T. Pérez-Prado, Mater. Character. 75, 101 (2013).

[2] S.R. Agnew, J.A. Horton, T.M. Lillo, D.W. Brown, Scr. Mater. 50, 377 (2004).

[3] E. Schmid, W. Boas, Plasticity of Crystals, F.A. Huhges Co., London 1950.

[4] R.W.K. Honeycombe, The plastic deformation of metals, Edward Arnold, London 1984.

[5] K.H. Kim, Y.M. Koo, Mater. Lett. 57, 6 (2002).

[6] T. Obara, H. Yoshinga, S. Morozumi, Acta Metallurg. 21, 845 (1973).

[7] H. Tonda, S. Ando, Metallurg. Mater. Trans. 33A, 831 (2002).

[8] N. Stanford, M.R. Barnett, Int. J. Plast. 47, 165 (2013).

[9] H. Miura, X. Yang, T. Sakai, H. Nogawa, S. Miura, Y. Watanabe, J.J. Jonas, Philos. Mag. 85, 3553 (2005).

[10] A. Chapuis, J.H. Driver, Acta Mater. 59, 1986 (2011).

[11] T.Tanaka, H. Conrad, Acta Metallurg. 20, 1019 (1972).

[12] A.Akhtar, E. Tegstoonian, Acta Metallurg. 19, 655 (1971).

[13] N. Munroe, X. Tan, H. Gu, Scr. Mater. 36, 1383 (1997).

[14] X.L. Nan, H.Y. Wang, L. Zhang, J.B. Li, Q.C Jian, Scr. Mater. 67, 443 (2012).

[15] X.L. Nan, H.Y. Wang, Z.Q. Wu, E.S. Xue, L. Zhang, Q.C. Jiang, Scr. Mater. 68, 530 (2013).

[16] E.C. Burke, W.R. Hibbard, Trans. AIME 194, 295 (1952).

[17] A. Akhtar, E. Teghtsoonian, Metallurg. Trans. A 6, 2201 (1975).

[18] M.R. Barnett, Z. Keshavarz, A.G. Beer, X. Ma , Acta Mater. 56, 5 (2008).

[19] W.B. Hutchinson, M.R. Barnet, Scr. Mater. 63, 737 (2010).

[20] J. Koike, R. Ohyama, Acta Mater. 53, 1963 (2005).

[21] W. Tyson, Acta Metallurg. 15, 574 (1967).

[22] Mater. Science and Technology, Eds. R.W. Cahn, P. Haansen, E.J. Kramer, vol. Ed. K.H. Matucha, Vol. 8, Weinheim 2005, p. 123.

[23] W.F. Hosford, Mechanical Behavior of Mater., Cambridge University Press, Cambridge 2005.

[24] A. Akhtar, E. Teghstoonian, Acta Metallurg. 17, 1339 (1969).

[25] R.E. Reed-Hill, W.D. Robertson, 209, 496 (1957).

[26] B. Bhattacharya, M. Niewczas, Philos. Mag. 17, 2227 (2011).

[27] M.Z. Butt, M.K. Azam, I. Haq, H. Asla, Physica Status Solidi 136, 357 (1993).

[28] A. Akhtar, E. Teghstoonian, Acta Metallurg. 17, 1351 (1969).

[29] A. Akhtar, Metallurg. Trans. A 6, 1105 (1975). 